\title{
Erratum: Structure, Texture and Phases in 3D Printed IN718 Alloy Subjected to Homogenization and HIP Treatments. Metals 2017, 7, 196
}

\author{
Ahmad Mostafa ${ }^{1}$ (D), Ignacio Picazo Rubio ${ }^{1}$, Vladimir Brailovski ${ }^{2}$, Mohammad Jahazi ${ }^{2}$ and \\ Mamoun Medraj 1,3,* \\ 1 Mechanical and Materials Engineering Department, Khalifa University of Science and Technology, \\ Masdar Institute, P.O. Box 54224 Abu Dhabi, UAE; a.mostafa@concordia.ca (A.M.); \\ ignacio.picazo.rubio@gmail.com (I.P.R.) \\ 2 Department of Mechanical Engineering, École de Technologie Supérieure, 1100, Notre-Dame Street West, \\ Montreal, QC H3C 1K3, Canada; vladimir.brailovski@etsmtl.ca (V.B.); mohammad.jahazi@etsmtl.ca (M.J.) \\ 3 Mechanical Engineering Department, Concordia University, 15151 Rue Sainte Catherine West, \\ Montreal, QC H3G 2W1, Canada \\ * Correspondence: mmedraj@encs.concordia.ca; Tel.: +1-514-848-2424
}

Received: 2 August 2017; Accepted: 7 August 2017; Published: 16 August 2017

The authors wish to make the following corrections to the main text in the published paper [1]. In this paper, the weight of $\mathrm{CuCl}_{2}$ should be changed from $5 \mathrm{mg}$ to $5 \mathrm{~g}$ to provide accurate recipe for the IN718 etchant. The etchant is a standard solution and its composition must be accurately reported as " $5 \mathrm{~g}$ of $\mathrm{CuCl}_{2}, 100 \mathrm{cc}$ of $\mathrm{HCl}$ and $100 \mathrm{cc}$ of ethyl alcohol". And the text "Figures 11 and 12" in the first paragraph under Section 3.1.3 should be replaced by "Figures 13 and 14" so the reader can make proper connection between the text and figures.

The authors apologize for any inconvenience caused by these changes. The manuscript will be updated online and the previous version will remain available from the article webpage.

\section{Reference}

1. Mostafa, A.; Picazo Rubio, I.; Brailovski, V.; Jahazi, M.; Medraj, M. Structure, Texture and Phases in 3D Printed IN718 Alloy Subjected to Homogenization and HIP Treatments. Metals 2017, 7, 196. [CrossRef]

(C) 2017 by the authors. Licensee MDPI, Basel, Switzerland. This article is an open access article distributed under the terms and conditions of the Creative Commons Attribution (CC BY) license (http:/ / creativecommons.org/licenses/by/4.0/). 